\title{
Prevalence of Hypertension during Pregnancy in Benin: Results from STEPS Survey in 2015
}

\author{
Yessito Corine Nadège Houehanou ${ }^{*}$, Salimanou Ariyoh Amidou2 ${ }^{2}$, Didjoho Joël Arnaud Sonou ${ }^{3}$, \\ Maurice Agonnoudé1, Gwladys Nadia Gbaguidi' ${ }^{4}$, Maria-Conchéta Tchibozo ${ }^{4}$, Dismand Houinato ${ }^{4}$ \\ ${ }^{1}$ National Training School for Senior Technicians in Public Health and Epidemiological Surveillance (ENATSE), University of \\ Parakou, Parakou, Benin \\ ${ }^{2}$ National Program for the Control of Noncommunicable Diseases, Cotonou, Benin \\ ${ }^{3}$ University Cardiology Clinic, CNHU-HKM, Cotonou, Benin \\ ${ }^{4}$ Laboratory of Chronic and Neurological Disease Epidemiology (LEMACEN), Faculty of Health Sciences, University of \\ Abomey-Calavi, Cotonou, Benin \\ Email: *yessito_fr@yahoo.fr
}

How to cite this paper: Houehanou, Y.C.N., Amidou, S.A., Sonou, D.J.A., Agonnoudé, M., Gbaguidi, G.N., Tchibozo, M.-C. and Houinato, D. (2021) Prevalence of Hypertension during Pregnancy in Benin: Results from STEPS Survey in 2015. Open Journal of Epidemiology, 11, 284-292. https://doi.org/10.4236/ojepi.2021.113025

Received: May 17, 2021

Accepted: August 21, 2021

Published: August 24, 2021

Copyright (c) 2021 by author(s) and Scientific Research Publishing Inc. This work is licensed under the Creative Commons Attribution International License (CC BY 4.0).

http://creativecommons.org/licenses/by/4.0/

(c) (i) Open Access

\begin{abstract}
Introduction: Hypertension disorders of pregnancy are one of the leading causes of maternal and fetal deaths. We aimed to estimate the prevalence of hypertension among pregnant women having participated in the STEPS survey in Benin in 2015. Methods: This was a database analysis. STEPS survey included consenting adults aged 18 to 69 years, living in Benin for at least 6 months prior to the survey. The participants were selected in households by a three-stage random sampling technique. The World Health Organization (WHO) STEPS instrument was used for data collection. After an individual interview with the participant at home, blood pressure was measured according to WHO recommendations. Pregnant women database was extracted for analysis. A multivariable logistic regression was done for associated factors identification. Results: A total of 2800 women (out of 5127 people) participated in the STEPS study of which 240 declared to be pregnant. The mean age was $28.9 \pm 6.8$ years. The prevalence of hypertension was $13.3 \%$. Severe hypertension represented $2.9 \%$. Hypertension during pregnancy was associated with primary school education level (compared to none, adjusted $\mathrm{OR}=$ $0.3,95 \% \mathrm{CI}[0.1-0.9], \mathrm{p}=0.042$ ). No significant association was found with behavioral factors. Conclusion: The prevalence of hypertension during pregnancy is high in Benin. In-depth studies and targeted interventions for prevention should be implemented.
\end{abstract}

\section{Keywords}

Hypertension, Pregnancy, Benin 


\section{Introduction}

Hypertensive disorders in pregnancy (HDP) constitute a major health concern worldwide because of their frequency, mortality and complex management. They can be classified into four categories: gestational hypertension, preeclampsia-eclampsia, chronic hypertension, chronic hypertension with superimposed preeclampsia [1].

HDP affect globally $5 \%-10 \%$ of pregnant women and are one of the leading causes of maternal mortality [2]. They were responsible for around $14.0 \%$ of maternal deaths in 2014 [3]. Furthermore, preeclampsia-eclampsia may increase the risk of cardiovascular disease after the pregnancy [4].

HDP remain a public health problem in sub-Saharan Africa (SSA), despite progress made in improving maternal health. The pooled prevalence was estimated at $5 \%-10 \%$ in systematic reviews, similar to the global estimate [5] [6] [7]. The mortality was estimated in 2014 at $16.0 \%$ [3]. Benin like most countries in SSA faces high maternal mortality. In 2017, the maternal mortality rate in Benin was 397 deaths (291 - 570) per 100,000 live births versus a world average of 211 (199 - 243) [8]. The report on the emergency obstetric and neonatal care needs in Benin estimated in 2016 that preeclampsia and eclampsia represented the second direct obstetrical cause of maternal deaths (22.5\%) [9].

Most deaths attributable to HDP are preventable. Usually, blood pressure (BP) is lower during pregnancy. Hypertension should be detected and managed appropriately before the onset of the preeclampsia and complications. The availability of epidemiological data allows local health systems to elaborate targeted preeclampsia prevention strategies. The WHO STEPwise Approach to NCD Risk Factor Surveillance (STEPS) is a simple, standardized method for collecting, analysing and disseminating data on key NCD risk factors in countries.

We aimed to estimate the prevalence of hypertension and to identify its associated factors among pregnant women in Benin in 2015 from STEPS survey data.

\section{Methods}

\subsection{Study Design, Population and Data Collection}

This was a secondary analysis of 2015 Benin STEPS survey data. The methodology of the STEPS survey in Benin in 2015 was previously described [10]. This was a cross-sectional study. It included consenting adults aged 18 to 69 years old, living in Benin for at least 6 months prior to the survey. People who are not able to respond to face-to-face interviews and those not met at home after 2 visits were not included. The study received approval from the National Ethics Committee for Health Research. Data were managed with confidentiality.

Participants were selected using a three-stage random sampling technique. The sampling database was provided by the National Institute of Statistics and Economic Analysis. At the first stage, 260 Enumeration Areas (EA) were randomly selected. Then, the list of households was established per retained EA and 20 households were randomly selected. At the third stage, one person was ran- 
domly chosen per household using the Kish method recommended for STEPS surveys [11]. The sample size was estimated at 5123 participants. It was calculated using a spreadsheet designed by the World Health Organization (WHO) to calculate the sample size in the STEPS surveys considering the following parameters: a cluster effect of 1.5 ; an alpha risk of $5 \%$, a theoretical prevalence of $50 \%$, a relative accuracy of $5 \%$, a predicted response rate of $90 \%$ and a stratification effect of 8.

The latest electronic form of the WHO STEPS instrument was used for data collection. It includes information on sociodemographic factors, lifestyle, pregnancy, history of hypertension and the recording of BP values. After an individual interview with the participant (STEP1), BP was measured according to WHO STEPS manual instructions (STEP2) [11]. It was measured in a seated position after at minimal 15-minute rest, in the left arm with an electronic device (Boso Medicus UNO, Bosch \& Sohn, Germany) with suitable cuff (22 - $32 \mathrm{~cm}$ or 32 $48 \mathrm{~cm}$ ). Three consecutive measures at 3-minute interval were taken and $\mathrm{BP}$ corresponded to the mean of the last two measurements.

\subsection{Variables}

The main outcome was "hypertension during pregnancy". Pregnancy was self-reported and hypertension was defined by systolic BP $\geq 140 \mathrm{~mm} \cdot \mathrm{Hg}$ or diastolic BP $\geq 90 \mathrm{~mm} \mathrm{Hg}$ or taking antihypertensive drug. Severe hypertension was defined by systolic BP $\geq 160 \mathrm{~mm} \cdot \mathrm{Hg}$ or diastolic $\mathrm{BP} \geq 110 \mathrm{~mm} \cdot \mathrm{Hg}$.

The behavioral factors were defined as follows: low fruit and vegetable intake by consumption of less than 5 servings of fruit and vegetable per day; low physical activity practice by practice less than 150 minutes of moderate physical activity or equivalent per week; tobacco consumption by tobacco smoking before or during pregnancy; excessive salt consumption by the report "often or always" for at least one of these questions: 1) "Do you often add salt or a salty sauce like soy sauce to your dish just before or while you eat it?" 2) "Do you often eat cooked meals that are high in salt (salty snacks, salted preserves, savory fast food dishes)?" or "too much" for this question: 3) "How much salt or salty sauce do you think you eat?".

\subsection{Data Management and Statistical Analysis}

The data of pregnant women were extracted from STEPS database and analysed using Epi Info version 7.1.5.2 software (CDC Atlanta, USA). The categorical variables were reported as proportions. Continuous variables were summarized with means \pm standard deviation for normal variables. The proportions were compared between two groups through chi-square or exact Fischer tests. A multivariable logistic regression was performed to identify associated factors with hypertension by using step-by-step downward approach. All variables with a p-value $\geq 0.2$ were introduced in the first model. The adjusted odds ratio and their confidence intervals at $95 \%$ were determined. For comparisons, p-value 
under 0.05 was considered significant.

\section{Results}

\subsection{Characteristics of Sample}

A total of 5127 people participated in the STEPS Benin survey of which 2800 were women. Of these, 240 were pregnant. They had a mean age of $28.9 \pm 6.8$ years with extremes of 18 and 47 years. The sociodemographic data are presented in the two first columns of Table 1 . The age group " 28 - 37" years was the most represented (50.0\%). Almost all (93.7\%) were married or lived as a couple. More than half (52.9\%) had no formal education and only $16.3 \%$ secondary level or more. Most of them (62.3\%) practiced liberal activity. The majority (77.1\%) had a monthly income below the official minimum wage 80 USD.

None of them reported smoking (Table 2). Alcohol consumption during last 30 days $(12.5 \%)$, low fruit and vegetable intake (92.9\%), low physical activity practice $(46.7 \%)$ and excessive salt intake (24.2\%) were reported (Table 2).

Table 1. Prevalence of hypertension among pregnant women according to sociodemographic characteristics, Benin STEPS survey 2015.

\begin{tabular}{|c|c|c|c|c|c|}
\hline & \multirow{2}{*}{$\mathrm{N}(\%)$} & \multicolumn{4}{|c|}{ Hypertension } \\
\hline & & $\mathrm{n}(\%)$ & Crude OR & $95 \% \mathrm{CI}$ & $\mathrm{p}$ \\
\hline Age (years) & & & & & 0.240 \\
\hline $18-27$ & $83(34.6)$ & $11(13.3)$ & 1 & & \\
\hline $28-37$ & $120(50.0)$ & $8(10.8)$ & 0.8 & $0.3-1.9$ & \\
\hline $38-47$ & $37(15.4)$ & $13(21.6)$ & 1.8 & $0.7-4.9$ & \\
\hline School education level & & & & & 0.091 \\
\hline None & $127(52.9)$ & $22(17.3)$ & 1 & & \\
\hline Primary & $74(30.8)$ & $5(6.8)$ & 0.3 & $0.1-0.9$ & \\
\hline Secondary or more & $39(16.3)$ & $5(12.8)$ & 0.7 & $0.2-2.0$ & \\
\hline Marital status & & & & & 0.388 \\
\hline Couple & $224(93.7)$ & $31(13.8)$ & 1 & & \\
\hline Alone/divorced/widower & $16(6.3)$ & $1(6.3)$ & 0.41 & $0.1-3.3$ & \\
\hline Occupation & & & & & 0.833 \\
\hline Independents & $149(62.3)$ & $21(14.1)$ & 0.9 & $0.3-3.1$ & \\
\hline Housewives & $63(26.4)$ & $7(11.1)$ & 0.8 & $0.2-2.8$ & \\
\hline Others & $28(11.3)$ & $4(14.3)$ & 1 & & \\
\hline Monthly income (USD) & & & & & 0.546 \\
\hline$<80$ & $185(77.1)$ & $24(13.8)$ & 1 & & \\
\hline$\geq 80$ & $55(22.9)$ & $6(10.9)$ & 0.7 & $0.3-1.9$ & \\
\hline
\end{tabular}

OR: Odd ratio; CI: Confidence Interval; N: Total number; n: Subgroup number. 
Table 2. Prevalence of hypertension according to behavioral characteristics among pregnant women, Benin STEPS survey 2015.

\begin{tabular}{|c|c|c|c|c|c|}
\hline & \multicolumn{5}{|c|}{ Hypertension } \\
\hline & $\mathrm{N}(\%)$ & n (\%) & Crude OR & $95 \% \mathrm{CI}$ & $\mathrm{p}$ \\
\hline \multicolumn{6}{|l|}{ Smoking } \\
\hline No & $240(100.0)$ & $33(100.0)$ & - & - & - \\
\hline Yes & $0(0.0)$ & $0(0.0)$ & & & \\
\hline Alcohol consumption last 30 days & & & & & 0.565 \\
\hline No & $210(87.5)$ & $29(13.8)$ & 1 & & \\
\hline Yes & $30(12.5)$ & $3(10.0)$ & 0.7 & $0.2-2.4$ & \\
\hline Low fruits and vegetables intake & & & & & $0.043^{*}$ \\
\hline No & $17(7.1)$ & $5(29.4)$ & 1 & & \\
\hline Yes & $223(92.9)$ & $27(12.1)$ & 0.3 & $0.1-0.9$ & \\
\hline \multicolumn{6}{|l|}{ Low physical activity practice } \\
\hline No & $112(46.7)$ & $15(11.7)$ & 1 & & 0.431 \\
\hline Yes & $128(53.3)$ & $17(15.2)$ & 1.3 & $0.6-2.8$ & \\
\hline Excessive salt intake & & & & & 0.905 \\
\hline No & $182(75.8)$ & $24(13.2)$ & 1 & & \\
\hline Yes & $58(24.2)$ & $8(13.8)$ & 1.1 & $0.4-2.5$ & \\
\hline
\end{tabular}

OR: Odd ratio; CI: Confidence interval; N: Total number; $n$ : subgroup number; ${ }^{*}$ statistically significant.

Mean systolic and diastolic BP among non-hypertensive women were $111.9 \pm$ $10.7 \mathrm{~mm} \mathrm{Hg}$ and $72.6 \pm 8.6 \mathrm{~mm} \mathrm{Hg}$, respectively, whereas mean systolic and diastolic BP among hypertensive women were $137.1 \pm 20.1 \mathrm{~mm} \mathrm{Hg}$ and $91.7 \pm 10.6$ $\mathrm{mm} \mathrm{Hg}$, respectively.

\subsection{Prevalence of Hypertension during Pregnancy and Associated Factors}

A total of 28 women had high BP during the survey and 7 were taking antihypertensive drugs; 32 met hypertension criteria defined in this work. The prevalence of hypertension during pregnancy was estimated at $13.3 \%$ (95\% CI [9.3 18.3]). Severe hypertension was noted in 7 women (2.9\%).

Hypertension during pregnancy was associated with primary school education level: versus none, adjusted $\mathrm{OR}=0.3,95 \%$ CI [0.1 - 0.9], $\mathrm{p}=0.042$ (Table 3). Pregnant women having primary school level had lower prevalence of hypertension compared to those without school education. No significant association was noted between hypertension during pregnancy and behavioral factors.

\section{Discussion}

This work focused on pregnant women recruited during the STEPS survey in Benin in 2015, having a mean age about 29 years. It showed that more than tenth 
Table 3. Factors associated to hypertension among pregnant women, Benin STEPS survey 2015.

\begin{tabular}{cccc}
\hline & \multicolumn{3}{c}{ Hypertension } \\
\cline { 2 - 4 } & Adjusted OR & $95 \%$ CI & $\mathrm{p}$ \\
\hline School education level (primary/none) & 0.3 & $0.1-0.9$ & $0.042^{*}$ \\
School education level (secondary or more/none) & 0.7 & $0.2-2.0$ & 0.492 \\
Low fruits and vegetables intake (yes/no) & 0.3 & $0.1-1.0$ & 0.052 \\
\hline
\end{tabular}

OR: odd ratio; CI: confidence interval; ${ }^{*}$ statistically significant.

of them had hypertension. The prevalence of hypertension was higher among pregnant women without education compared to others.

The mean age of this sample is in the age range found by other authors in Togo in 2014 (30 years) [12] and in Tanzania in 2015 (27 years) [13].

The prevalence of hypertension during pregnancy (13.3\%) in this work was similar to that reported by Baragou et al., in Togo in 2014 (12.3\% in a teaching hospital) [12]. It is lower than those reported in Zimbabwe in 2015 (19.4\% in Harare maternities) [14], Botswana in 2016 (22.2\% in eight of the largest public hospitals) [15], Republic of Democratic Congo in 2016 (26.7\% in Kinshasa antenatal clinics) [16], Nigeria in 2017 (16.7\% in a teaching hospital) [17], and Ethiopia in 2019 (16.8\% in Gondar town public health institutions) [18]. However, it is greater than that reported in Tanzania in 2015 (6.9\% in antenatal clinics) [13]. In the others world regions, 9.5\% was reported in Iran in 2014 (in a teaching hospital) [19], 10.2\% in India (from a community-based study) [20], $7.8 \%$ in France in 2020 (pooled prevalence in a review) [21]. The wide variations of the hypertension prevalence during pregnancy could be linked to differences of women's lifestyle depending of cultures, health system performance, methodology and period of the study. Higher prevalence of hypertension during pregnancy in most of hospital-based studies could be explained by the fact that hospitals are referral centers supposed to manage more cases of HDP than peripheral health centers.

In this work, hypertension was not associated with age. However, some previous studies have shown that hypertension during pregnancy increase with the age of pregnant women [12] [13]. Hypertension is associated with the school level in this study. This result is in line with some literature data [22]. Indeed, women with formal education could have more access to health education and could more prevent hypertension during pregnancy. No independent association was found between hypertension and behavioral factors. However, a significant association had been found between hypertension and alcohol consumption in another study conducted in Ethiopia [18]. Elsewhere, it had been noted in a Congolese study that fruit and vegetable intake and physical activity practice are associated with a decrease of pregnancy induced hypertension risk [23].

The work targeted pregnant women from a representative sample of Beninese people in 2015. It provided data on hypertension during pregnancy, which could 
inform local authorities and community leaders. The design of the STEPS study (cross-sectional) and the recruitment in households could underestimate the prevalence of hypertension during pregnancy. Indeed, it could be that the complicated cases of hypertension during pregnancy were hospitalized during the visits and were not included in this survey. In addition, some information necessary to categorize hypertension and to explore other associated factors were not available (gynecologic-obstetric history, term of pregnancy, clinical and biological data on pregnancy). More specific studies will deepen the findings and better explore the factors associated with hypertension during pregnancy.

The results suggest the need to implement prevention measures (individual or collective) of hypertension during pregnancy which focus on behavioral factors, early detection and better management. The improvement of school education level is also necessary.

\section{Conclusion}

This study shows a high prevalence of hypertension during pregnancy in Benin especially among women with low level of education. It highlights the need to implement actions for the prevention of HDP and their complications taking to account level of education.

\section{Acknowledgements}

The authors thank the team of the National Program for Non-Communicable Disease Control in Benin for providing data.

\section{Conflicts of Interest}

The authors declare no conflicts of interest regarding the publication of this paper.

\section{References}

[1] American College of Obstetricians and Gynecologists (2013) Hypertension in Pregnancy: Executive Summary. Obstetrics \& Gynecology, 122, 1122-1131. https://doi.org/10.1097/01.AOG.0000437382.03963.88

[2] Regitz-Zagrosek, V., Roos-Hesselink, J., Bauersachs, J., Blomström-Lundqvist, C., Cífková, R., De Bonis, M., et al. (2018) 2018 ESC Guidelines for the Management of Cardiovascular Diseases during Pregnancy: The Task Force for the Management of Cardiovascular Diseases during Pregnancy of the European Society of Cardiology (ESC). European Heart Journal, 39, 3165-3241. https://academic.oup.com/eurheartj/article/39/34/3165/5078465

[3] Say, L., Chou, D., Gemmill, A., Tunçalp, Ö., Moller, A.-B., Daniels, J., et al. (2014) Global Causes of Maternal Death: A WHO Systematic Analysis. The Lancet Global Health, 2, e323-e333. https://doi.org/10.1016/S2214-109X(14)70227-X

[4] Brouwers, L., van der Meiden-van Roest, A.J., Savelkoul, C., Vogelvang, T.E., Lely, A.T., Franx, A., et al. (2018) Recurrence of Pre-Eclampsia and the Risk of Future Hypertension and Cardiovascular Disease: A Systematic Review and Meta-Analysis. BJOG: An International Journal of Obstetrics \& Gynaecology, 125, 1642-1654. 


\section{https://doi.org/10.1111/1471-0528.15394}

[5] Nyaga, U., Bigna, J.J., Jingi, A.M., Nansseu, J.R., Kaze, A.D., Fokom-Domgue, J., et al. (2018) Hypertensive Disorders of Pregnancy in Africa: A Systematic Review and Meta-Analysis. Journal of Hypertension, 36, e250.

https://doi.org/10.1097/01.hjh.0000549025.48813.65

[6] Noubiap, J.J., Bigna, J.J., Nyaga, U.F., Jingi, A.M., Kaze, A.D., Nansseu, J.R., et al. (2019) The Burden of Hypertensive Disorders of Pregnancy in Africa: A Systematic Review and Meta-Analysis. The Journal of Clinical Hypertension, 21, 479-488. https://doi.org/10.1111/jch.13514

[7] Gemechu, K.S., Assefa, N. and Mengistie, B. (2020) Prevalence of Hypertensive Disorders of Pregnancy and Pregnancy Outcomes in Sub-Saharan Africa: A Systematic Review and Meta-Analysis. Women's Health, 16. https://doi.org/10.1177/1745506520973105

[8] World Health Organization (2019) Maternal Mortality: Levels and Trends 2000 to 2017. https://www.who.int/publications/i/item/9789241516488

[9] Health Ministry of Benin (2020) Operational Plan for Maternal and Neonatal Mortality Reduction in Benin. https://www.prb.org/wp-content/uploads/2020/06/Benin-Plan-Operationnel-de-Re duction-de-la-Mortalite-Maternelle-et-Neonatale-au-Benin.pdf

[10] Health Ministry of Benin (2016) Final Report of the STEPS Survey in Benin. https://www.who.int/teams/noncommunicable-diseases/surveillance/data/benin

[11] World Health Organization (2017) WHO STEPS Surveillance Manual. https://www.who.int/teams/noncommunicable-diseases/surveillance/systems-tools/ steps/manuals

[12] Baragou, S., Goeh-Akue, E., Pio, M., Afassinou, Y.M. and Atta, B. (2014) Hypertension and Pregnancy in Lome (Sub-Saharan Africa): Epidemiology, Diagnosis and Risk Factors. Annales de Cardiologie et d'Angéiologie, 63, 145-150. https://doi.org/10.1016/j.ancard.2014.05.006

[13] Mwanri, A.W., Kinabo, J.L., Ramaiya, K. and Feskens, E.J.M. (2015) High Blood Pressure and Associated Risk Factors among Women Attending Antenatal Clinics in Tanzania. Journal of Hypertension, 33, 940-947. https://doi.org/10.1097/HJH.0000000000000501

[14] Muti, M., Tshimanga, M., Notion, G.T., Bangure, D. and Chonzi, P. (2015) Prevalence of Pregnancy Induced Hypertension and Pregnancy Outcomes among Women Seeking Maternity Services in Harare, Zimbabwe. BMC Cardiovascular Disorders, 15, 111. https://doi.org/10.1186/s12872-015-0110-5

[15] Johnson, K.M., Zash, R., Haviland, M.J., Hacker, M.R., Luckett, R., Diseko, M., et al. (2016) Hypertensive Disease in Pregnancy in Botswana: Prevalence and Impact on Perinatal Outcomes. Pregnancy Hypertension, 6, 418-422.

https://doi.org/10.1016/j.preghy.2016.10.002

[16] Nkamba, D.M., Ditekemena, J., Wembodinga, G., Bernard, P., Tshefu, A. and Robert, A. (2019) Proportion of Pregnant Women Screened for Hypertensive Disorders in Pregnancy and Its Associated Factors within Antenatal Clinics of Kinshasa, Democratic Republic of Congo. BMC Pregnancy Childbirth, 19, Article No. 297. https://doi.org/10.1186/s12884-019-2435-Z

[17] Singh, S., Ahmed, E.B., Egondu, S.C. and Ikechukwu, N.E. (2014) Hypertensive Disorders in Pregnancy among Pregnant Women in a Nigerian Teaching Hospital. Nigerian Medical Journal, 55, 384-388. https://doi.org/10.4103/0300-1652.140377

[18] Walle, T.A. and Azagew, A.W. (2019) Hypertensive Disorder of Pregnancy Preva- 
lence and Associated Factors among Pregnant Women Attending Ante Natal Care at Gondar Town Health Institutions, North West Ethiopia 2017. Pregnancy Hypertension, 16, 79-84. https://doi.org/10.1016/j.preghy.2019.03.007

[19] Khosravi, S., Dabiran, S., Lotfi, M. and Asnavandy, M. (2014) Study of the Prevalence of Hypertension and Complications of Hypertensive Disorders in Pregnancy. Open Journal of Preventive Medicine, 4, 860-867. https://doi.org/10.4236/ojpm.2014.411097

[20] Magee, L.A., Sharma, S., Nathan, H.L., Adetoro, O.O., Bellad, M.B., Goudar, S., et al. (2019) The Incidence of Pregnancy Hypertension in India, Pakistan, Mozambique, and Nigeria: A Prospective Population-Level Analysis. PLOS Medicine, 16, e1002783. https://doi.org/10.1371/journal.pmed.1002783

[21] Olié, V., Moutengou, E., Deneux-Tharaux, C., Kretz, S., Vallée, A., Blacher, J., et al. (2020) Prevalence of Hypertensive Disorders during Pregnancy and Post-Partum in France. Archives of Cardiovascular Diseases Supplements, 12, 155-156. https://doi.org/10.1016/j.acvdsp.2019.09.321

[22] Meazaw, M.W., Chojenta, C., Muluneh, M.D. and Loxton, D. (2020) Factors Associated with Hypertensive Disorders of Pregnancy in Sub-Saharan Africa: A Systematic and Meta-Analysis. PLoS ONE, 15, e0237476.

https://doi.org/10.1371/journal.pone.0237476

[23] Longo-Mbenza, B., Kadima-Tshimanga, B., Buassa-bu-Tsumbu, B. and M'buyamba, K. (2008) Diets Rich in Vegetables and Physical Activity Are Associated with a Decreased Risk of Pregnancy Induced Hypertension among Rural Women from Kimpese, DR Congo. Nigerian Journal of Medicine, 17, 45-49.

https://doi.org/10.4314/njm.v17i1.37354 